\title{
PKM PENERAPAN TEKNOLOGI INFORMASI SEBAGAI SARANA KEGIATAN BELAJAR MENGAJAR BAGI GURU- GURU SD NEGERI TUGU 1 CIMANGGIS KOTA DEPOK)
}

\author{
Rini Amalia ${ }^{1 *}$, Sri Melati Sagita ${ }^{2}$, Achmad Faisal $^{3}$ \\ ${ }^{123}$ Teknik Informatika, Universitas Indraprasta PGRI \\ * Reen.amaleea@yahoo.com
}

\begin{abstract}
ABSTRAK. Saat ini, kasus coronavirus disease atau dikenal dengan istilah covid-19 di Indonesia telah terjadi lonjakan yang besar. Hal ini menjadi kekhawatiran karena kasus ini akan terus membesar risikonya dan mengancam banyak sektor, termasuk dunia pendidikan. Kini pendekatan pembelajaran telah berubah ke arah pembelajaran abad pengetahuan. Orang dapat belajar di mana saja, kapan saja, dengan siapa saja. Itulah ciri pembelajaran abad pengetahuan yang dikenal sebagai berbasis komputer, model pembelajaran daring atau Online Learning Model (OLM). Oleh karena itu proses belajar mengajar harus memanfaatkan dan menerapkan teknologi informasi. Beralihnya pembelajaran model konvesional dengan model pembelajaran daring, didapati beberapa kendala. Kendala pertama adalah kesiapan perangkat dan tentu paket data internet, kedua tidak semua guru dan murid siap mengoperasikan sistem pembelajran daring dengan cepat, termasuk juga mempersiapkan bahan pembelajaran secara digital. Para guru dan murid diharapkan mulai mentransfer pengetahuan dan ketramplian agar lebih kreatif dan inovatif dalam belajar, menerapkan teknologi Informasi agar dimanfaatkan seluasluasnya untuk menatap hari depan lebih cerah. Salah satu yang bisa dilakukan ialah penerapan teknologi informasi dengan pembelajaran daring atau Online Learning Model (OLM) dengan memiliki ketrampilan mengunakan aplikasi bandicam dan google form.
\end{abstract}

Kata Kunci : Teknologi Informasi , Bandicam, Google Form.

ABSTRACT. Currently, cases of coronavirus disease or known as covid-19 in Indonesia have experienced a large spike. This is a concern because this case will continue to increase the risk and threaten many sectors, including the world of education. Now the learning approach has changed towards learning the age of knowledge. People can study anywhere, anytime, with anyone. That is the characteristic of learning in the knowledge age known as computer-based, online learning model or Online Learning Model (OLM). Therefore, the teaching and learning process must utilize and apply information technology. Shifting the conventional learning model to the online learning model, several obstacles were found. The first obstacle is the readiness of the device and of course internet data packages, secondly, not all teachers and students are ready to operate the online learning system quickly, including preparing digital learning materials. Teachers and students are expected to start transferring knowledge and skills to be more creative and innovative in learning, applying information technology to be used as widely as possible to look to a brighter future. One thing that can be done is the application of information technology with online learning or Online Learning Model (OLM) by having the skills to use bandicam and google form applications.

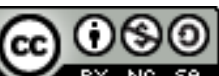

This work is licensed under a Creative Commons Attribution-NonCommercial-ShareAlike 4.0 International License. 
Keywords: Information Technology, Bandicam, Google Form.

\section{PENDAHULUAN}

SD Negeri Tugu 1 yang berada pada wilayah Cimanggis kota Depok. SD Negeri Tugu 1 berlokasi di J1. Pd. Pesantren N0. 9C, Pasir Gn. Sel., Kec Cimanggis kota Depok. Teknologi Informasi dan Komunikasi sudah diperkenalkan di semua jenjang Pendidikan termasuk sekolah Dasar. Menurut Bambang teknologi informasi adalah sarana dan prasarana (hardware, software, useware) sistem dan metode untuk memperoleh, mengirimkan, mengolah, menafsirkan, menyimpan, mengorganisasikan, dan menggunakan data secara bermakna.[1] Saat ini, dunia memang sedang tergoncang oleh kasus coronavirus disease atau dikenal dengan istilah covid-19 sejak akhir tahun lalu. Di Indonesia sendiri terjadi lonjakan yang besar pada kasus covid-19. Tentu menjadi kekhawatiran karena kasus ini akan terus membesar risikonya dan mengancam banyak sektor, termasuk dunia pendidikan. kini pendekatan pembelajaran telah berubah ke arah pembelajaran abad pengetahuan. Orang dapat belajar di mana saja, kapan saja, dengan siapa saja. Itulah ciri pembelajaran abad pengetahuan yang dikenal sebagai berbasis komputer atau model pembelajaran daring atau Online Learning Model (OLM)

- Menginspirasi dan menjadi fokus pelaksanaan kegiatan PPM; dapat berupa tantangan institusi perguruan tinggi, persoalan atau kebutuhan usaha kecil /menengah, pemberdayaan masyarakat, penerapan teknologi tepat guna.

- Kondisi eksisting sumber daya usaha kecil/menengah, masyarakat atau PT.

- Upaya-upaya yang pernah diterimakan pihak lain kepada usaha kecil/menengah, masyarakat atau PT.

- Tujuan utama kegiatan

\section{Tinjauan Pustaka}

Beralihnya pembelajaran model konvesional dengan model pembelajaran daring, didapati beberapa kendala. Kendala pertama adalah kesiapan perangkat dan tentu paket data internet, kedua tidak semua guru dan murid siap mengoperasikan sistem pembelajaran daring dengan cepat, termasuk juga mempersiapkan bahan pembelajaran secara digital. Para guru dan murid diharapkan mulai mentransfer pengetahuan dan ketramplian agar lebih kreatif dan inovatif dalam belajar, memanfaatkan perkembangan teknologi komunikasi dan digital agar dimanfaatkan seluas-luasnya untuk menatap hari depan lebih cerah. Ada banyak inisiatif yang bisa dilakukan untuk tetap bersiasat di tengah kesulitan. Di dunia pendidikan, bisa memanfaatkan kemerdekaan berpikirnya untuk lepas dari masalah dan menatap masa depan dengan optimistis. Salah satu yang bisa dilakukan ialah pembelajaran dengan daring atau Online Learning Model (OLM)

\section{Online Learning Model (OLM)}

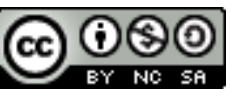

This work is licensed under a Creative Commons Attribution-NonCommercial-ShareAlike 4.0 International License. 
Merupakan suatu sistem yang dapat memfasilitasi siswa belajar lebih luas, lebih banyak, dan bervariasi. Melalui fasilitas yang disediakan oleh sistem tersebut, siswa dapat belajar kapan dan dimana saja tanpa terbatas oleh jarak, ruang dan waktu. Pembelajaran yang disusun dengan tujuan menggunakan sistem elektronik atau komputer sehingga mampu mendukung proses pembelajaran. E-learning adalah suatu sistem atau konsep pendidikan yang memanfaatkan teknologi informasi dalam proses belajar mengajar. Berikut beberapa pengertian E-learning dari berbagai sumber:

a. Proses pembelajaran jarak jauh dengan menggabungkan prinsip-prinsip dalam proses pembelajaran dengan teknologi [2]

b. Sistem pembelajaran yang digunakan sebagai sarana untuk proses belajar mengajar yang dilaksanakan tanpa harus bertatap muka secara langsung antara guru dengan siswa [3]

\section{Karakteristik E-learning}

Menurut [4] Karakteristik E-Learning adalah

a. Memanfaatkan jasa teknologi elektronik; di mana guru dan siswa, siswa dan sesama siswa atau guru dan sesama guru dapat berkomunikasi dengan relatif mudah dengan tanpa dibatasi oleh hal-hal yang protokoler.

b. Memanfaatkan keunggulan komputer (digital media dan computer networks).

c. Menggunakan bahan ajar bersifat mandiri (self learning materials) disimpan di komputer sehingga dapat diakses oleh guru dan siswa kapan saja dan di mana saja bila yang bersangkutan memerlukannya.

d. Memanfaatkan jadwal pembelajaran, kurikulum, hasil kemajuan belajar dan hal-hal yang berkaitan dengan administrasi pendidikan dapat dilihat setiap saat di komputer.

\section{METODE}

Metode Pendekatan dan Penerapan IPTEK dengan menggunakan metode pendekatan kegiatan IbM adalah dengan melakukan wawancara kepada kepala sekolah untuk mengetahui materi Teknologi Informasi dan Komunikasi guna mendapatkan gambaran kebutuhan mitra sehingga produk yang diciptakan dapat memberikan manfaat dan solusi yang tepat.

Partisipasi mitra dalam pelaksanaan program :

a. Guna tercapainya tujuan dari kegiatan ini diharapkan mitra dapat memberikan informasi yang dianggap mampu mendukung kegiatan IbM berkenaan dengan kegiatan pembelajaran / pelatihan.

b. Melakukan pengujian terhadap produk yang diciptakan.

c. Implementasi produk dalam kegiatan pembelajaran/ pelatihan.

\section{HASIL DAN PEMBAHASAN}

Hasil yang sudah dicapai dalam pengabdian kepada masyarakat (IbM) adalah :

1. Kegiatan sosialisasi dan wawancara

Kegiatan sosialisasi dan wawancara secara lisan kepada stock holder dalam hal ini kepala sekolah SD

Negeri Tugu 1 Depok, diperoleh informasi bahwa guru memerlukan ketrampilan dan pemahaman

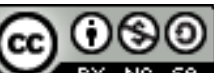

This work is licensed under a Creative Commons Attribution-NonCommercial-ShareAlike 4.0 International License. 
TRIDHARMADIMAS: Jurnal Pengabdian Kepada Masyarakat Jayakarta http://journal.stmikjayakarta.ac.id/index.php/tridharmadimas EmaiL: info@stmik.jayakarta.ac.id , tridharmadimas.jayakarta@gmail.com DOI : 10.52362/tridharmadimas.v1i2.658 /halaman : 123-129 E-ISSN: 2798-8295 (Online), P-ISSN: 2798-8554 (Print) Vol. 1, No.2, Desember 2021

menggunakan Bandicam dan Google FormBagian ini memuat data (dalam bentuk ringkas), analisis data dan interpretasi terhadap hasil statistik. Teori-teori yang sudah ada digunakan pada bagian ini untuk interpretasi, tentu saja bukan dengan copy and paste, tapi dengan penyesuaian kalimat sebagai interpretasi. Jika dilihat dari proporsi tulisan, bagian ini harusnya mengambil proporsi terbanyak, dapat mencapai 50\% atau lebih.

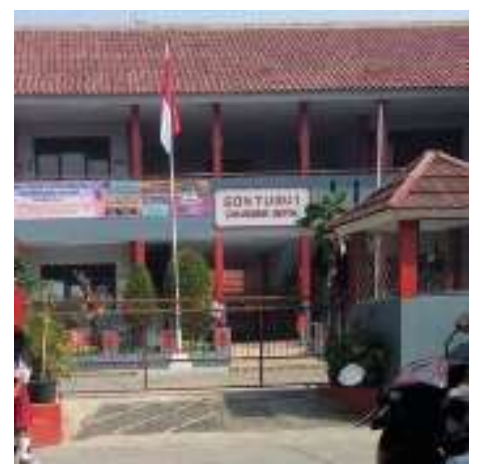

Gambar 1 Lokasi Pelatihan

2. Menyiapkan Peralatan Kegiatan

Dari hasil wawancara di awal tim pelaksana menyiapkan materi pelatihan dengan memperhatikan usulan dari pihak sekolah atau sesuai kebutuhan guru. Materi yang diberikan dalam pelatihan adalah Bandicam dan Google Form. Dikarenakan pelaksanaan kegiatan pada saat pandemi Covid-19, maka tim menyiapkan pelatihan dengan memperhatikan protokol kesehatan.

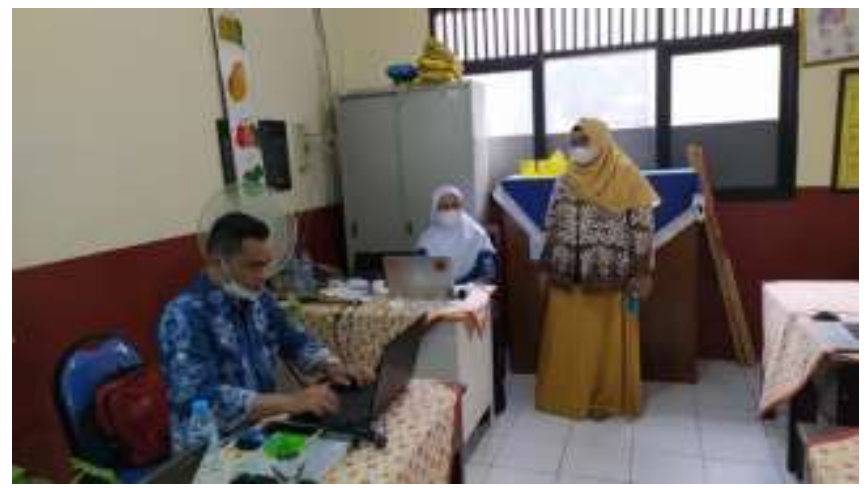

Gambar 2. Persiapan Perangkat Pelatihan

3. Pelaksanaan Kegiatan

This work is licensed under a Creative Commons Attribution-NonCommercial-ShareAlike 4.0 International License. 
Pada pelaksaan kegiatan tim memberikan pelatihan memperhatikan protokol kesehatan. Memberikan pengetahuan dasar tentang Bandicam dan Google Form kemudian melakukan implementasi penggunaan Bandicam dan Google Form kepada guru SD Negeri Tugu 1 Depok.Tim Pelaksana memberikan contoh penggunaan Bandicam seperti merekam layar komputer dilanjutkan dengan penggunaan Google Form seperti membuat pertanyaan pilihan ganda, jawaban singkat, memasukan gambar, mengirimkan formulir ke responden, menyimpan formulir dan lain sebagainya. Para peserta pelatihan mencoba mempraktekan materi yang sudah diberikan oleh tim. Pelatihan berjalan dengan baik sampai dengan langkah pembuatan aplikasi yang terakhir. Kemudian pada sesi berikutnya para peserta pelatihan diminta membuat aplikasi sendiri sesuai dengan kemampuan masing-masing. Pada sesi pembuatan aplikasi sendiri, tidak semua peserta bisa menyelesaikan dengan sempurna. Hanya beberapa peserta yang dapat menyelesaikan dengan baik.

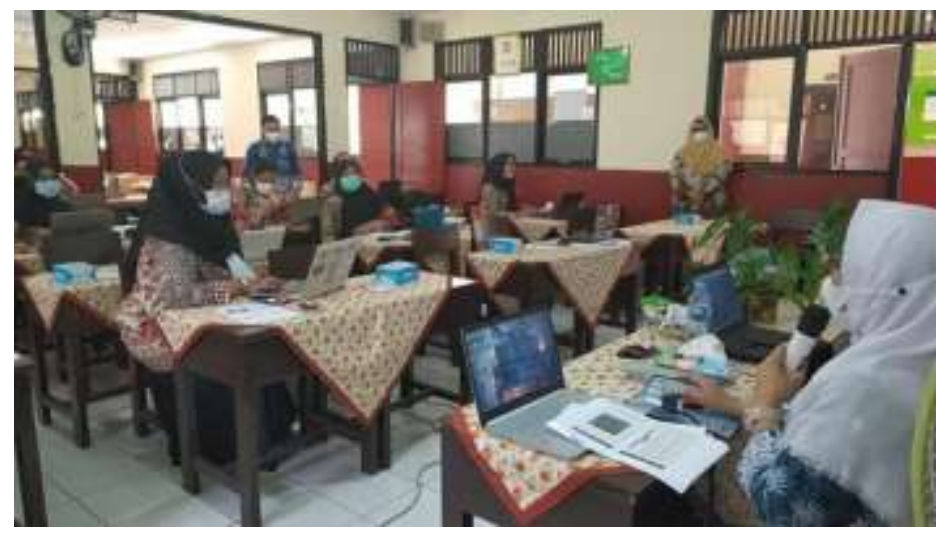

Gambar 3 Peserta Pelatihan

\section{Evaluasi Kegiatan}

Evaluasi kegiatan dilakukan evaluasi keseluruhan proses kegiatan IbM, mencakup mengevaluasi kelebihan dan kekurangan dari modul pembelajaran menggunakan Bandicam dan Google Form yang telah disampaikan kepada peserta pelatihan. Secara keseluruhan tidak ada kendala yang berarti, dalam pelaksanaan para peserta pelatihan sangat antusias dengan banyaknya pertanyaan yang diajukan. Dan pada saat mencoba membuat aplikasi, masih banyak yang belum mengetahui dasar-dasar penggunaan komputer dan penggunanan Bandicam dan Google Form. Dibutuhkan kesabaran dalam menjelaskan materi dan dalam pembuatan aplikasi pembelajaran menggunakan Bandicam dan Google Form. Akan tetapi ada beberapa peserta pelatihan yang sudah menguasai Bandicam dan Google Form dan mampu membuat kembali aplikasi sesuai kemampuannya

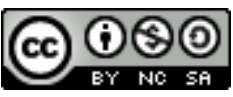

This work is licensed under a Creative Commons Attribution-NonCommercial-ShareAlike 4.0 International License. 
TRIDHARMADIMAS: Jurnal Pengabdian Kepada Masyarakat Jayakarta http://journal.stmikjayakarta.ac.id/index.php/tridharmadimas EmaiL: info@stmik.jayakarta.ac.id , tridharmadimas.jayakarta@gmail.com DOI : 10.52362/tridharmadimas.v1i2.658 /halaman : 123-129 E-ISSN: 2798-8295 (Online), P-ISSN: 2798-8554 (Print) Vol. 1, No.2, Desember 2021

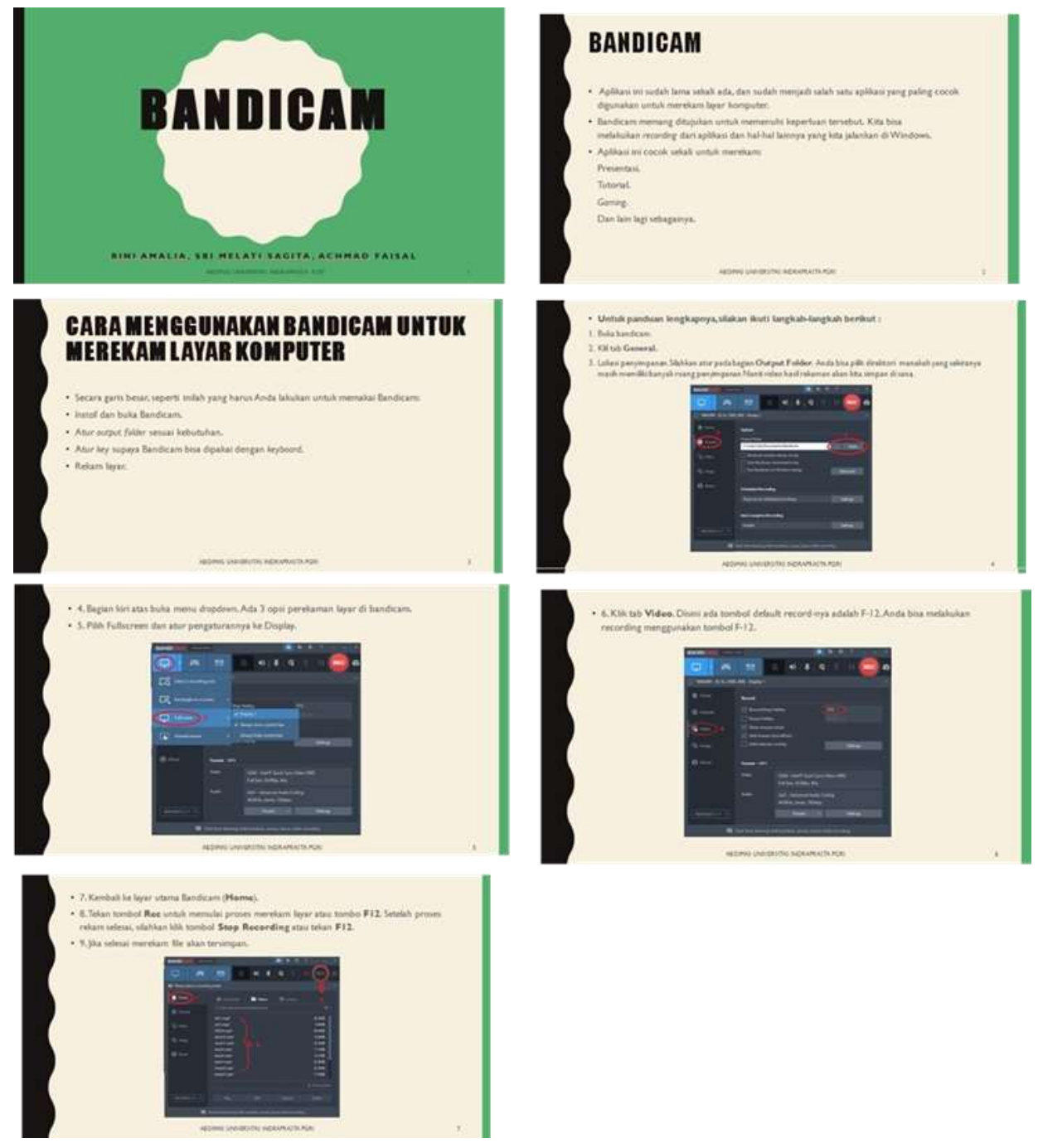

Gambar 4 Evaluasi Kegiatan

KESIMPULAN

Pada Kegiatan pengabdian masyarakat yang dilaksanakan pada SD Negeri Tugu 1 Kota Depok dapat dilaksanakan dengan baik. Para peserta sangat antusias dalam melaksanakan kegiatan pengabdian masyarakat yang diberikan oleh tim. Dengan kegiatan pelatihan ini, para guru dapat menggunakan dan

This work is licensed under a Creative Commons Attribution-NonCommercial-ShareAlike 4.0 International License. 


\section{TRIDHARMADIMAS: Jurnal Pengabdian Kepada Masyarakat Jayakarta}

http://journal.stmikjayakarta.ac.id/index.php/tridharmadimas

EmaiL: info@stmik.jayakarta.ac.id , tridharmadimas.jayakarta@gmail.com

DOI : 10.52362/tridharmadimas.v1i2.658 /halaman : 123-129

E-ISSN: 2798-8295 (Online), P-ISSN: 2798-8554 (Print) Vol. 1, No.2, Desember 2021

meningkatkan ketrampilan dalam menggunakan aplikasi Bandicam dan Google Form. Luaran pengabdian masyarakat adalah peningkatan ketrampilan para guru dalam menggunakan Bandicam dan Google Form Berdasarkan Hasil dan kesimpulan, dan dampak terhadap penelitian sebagai berikut:

1. Modul pembelajaran menggunakan Bandicam dan Google Form dapat dikembangkan kembali oleh pihak lain yang membutuhkan.

2. Ketersediaan peralatan teknologi yang memadai sehingga guru bisa lebih optimal meningkatkan ketrampilan komputer.

\section{DAFTAR PUSTAKA}

[1] Warsita, B. (2008). Teknologi pembelajaran landasan dan aplikasinya.

[2] Chandrawati, S. R. (2010). Pemamfaatan E-learning dalam Pembelajaran. Jurnal Cakrawala Kependidikan, 8(2).

[3] Ardiansyah, A. (2013). Meningkatkan Hasil belajar Pada Materi Pokok Hidrokarbon Melalui Model Pembelajaran Kooperatif Tipe TTW (Think Talk Write) Bermuatan Karakter siswa kelas X-4 SMAN 6 Banjarmasin. Quantum: Jurnal Inovasi Pendidikan Sains, 4(1).

[4] Suyanto, A. H. (2005). Mengenal E-learning. Universitas Gadjah Mada.[On-Line]. Tersedia: Http: Www. Asep-Hs. Web. Ugm. Ac. Id.

This work is licensed under a Creative Commons Attribution-NonCommercial-ShareAlike 4.0 International License. 